\title{
Impact of climate change on the occurrence and distribution of bluetongue in Europe
}

\author{
WIES $Ł A W ~ N I E D B A L S K I$, ANDRZEJ FITZNER
}

Department of Foot and Mouth Disease, National Veterinary Research Institute, Wodna 7, 98-220 Zduńska Wola, Poland

\section{Niedbalski W., Fitzner A. \\ Impact of climate change on the occurrence and distribution of bluetongue in Europe}

\section{Summary}

Climate changes may have significant impact on animal health, including changes in the distribution and seasonality of vector-borne diseases. Arboviruses, such as bluetongue virus (BTV), are particularly susceptible to climate change because of their small size and their ability to adapt to variations in the temperature of the environment. Climate also has long-term indirect effects on the transmission of BT via its effects on the distribution and availability of suitable habitats.

Changes in BT incidence in Europe have been matched by spatio-temporal changes in regional climates, including the specific climatic drivers of BTV infection. The climate changes are responsible for the occurrence and distribution of BT through their impact on the viral vectors. Changes in climate, i.e. temperature, precipitation, humidity, wind, etc., can influence various aspects of the Culicoides vectors' life cycle, including survival, population numbers, vector-pathogen interactions, pathogen replication, vector behaviour and, of course, its distribution.

Different species of Culicoides have different environmental tolerances, and the optimal temperature and humidity levels for populations of Afro-Asiatic species, such as C. imicola, are different from those for Palearctic species, such as the $\mathrm{C}$. obsoletus and $\mathrm{C}$. pulicaris groups. However, the biotic processes of changing vector roles and distribution have been as important as the climatic process in driving the invasion of Europe by multiple BTV strains. The enhanced transmission of BTV by indigenous European vectors has been instrumental in the spread and persistence of infection in cooler and wetter areas of different regions of Europe after the invasion. The vectorial capacity of Culicoides is dynamic and climate-mediated, making it difficult to state unequivocally that particular species cannot or will not be involved in transmission - even of strains that enter Europe unexpectedly from geographically remote regions.

Keywords: climate change, bluetongue, occurrence, distribution, Europe

Climate change is defined by the International Panel on Climate Change (IPCC) as "a statistically significant variation in either the mean state of the climate or in its variability, persisting for an extended period (typically decades or longer)" (https://www.ipcc.ch/). Climate change is usually perceived as global warming, including elevated mean temperatures and stronger temperature variations and extremes, but it also involves variation of environmental factors, including precipitation/humidity, drought frequency, ocean acidification, water quality, and seasonality. According to the $5^{\text {th }}$ Assessment Report (AR5) of the IPCC, the planet's mean air and ocean temperatures have been rising over the last century because of increasing concentration of heat-trapping greenhouse gasses (GHGs) in the atmosphere. As a result, a reduction in the amount of snow and ice and a rise in the sea level are observed. It is predicted that the global mean surface temperature is likely to increase by $0.3-0.7^{\circ} \mathrm{C}$ in 2016 -2035 relative to 1986-2005 (https://www.ipcc.ch/). The concentration of GHGs, especially of carbondioxide, methane, and nitrous oxide, has nearly doubled since the pre-industrial period due to anthropogenic activities such as the burning of fossil fuels, deforestation, industrialization and agricultural intensification. An increase in the mean global temperature can lead to tremendous changes in hydrological cycles and the overall global climate manifested by an increase in the frequency and intensity of extreme events, such as heavy precipitation, floods, heat waves, droughts and extreme tidal events. Environmental changes, such as flood protection through provision of new wetlands or increased urban greenspace to minimise urban heat effect, are designed to mitigate the effects of climate change (13). These changes have substantial effects on the epidemiology of infectious diseases 
of livestock. Particularly arthropods and the viruses (arboviruses) they transmit are highly sensitive to changes in temperature and other climatic variables that can alter vector physiology and behaviour, as well as the kinetics of viral replication. The fact that climate change will affect vector-borne diseases is widely recognised, especially because arthropods are ectothermal, and the extrinsic incubation of pathogens is largely temperature-dependent (1). Insect-borne pathogens such as bluetongue virus (BTV) are particularly susceptible to climate change because of their small size and their ability to adapt to variations in the temperature of the environment (poikilothermy) (23). BTV belongs to the genus Orbivirus within the family Reoviridae, and to date, twenty seven immunologically distinct serotypes of BTV have been identified worldwide (36). Bluetongue (BT), caused by this virus, is an infectious but non-contagious viral disease of domestic and wild ruminant species, including sheep, goats and cattle (12). The most common signs of the disease include fever, catarrhal, stomatitis, rhinitis, enteritis and lameness. BTV is transmitted between its ruminant hosts by certain species of biting midges of the genus Culicoides, family Ceratopogonidae (17). They are small $(<3 \mathrm{~mm})$ haematophagous insects that occur in every inhabited continent in the world and breed in a wide variety of semi-aquatic sites, including tree holes, rotting vegetation, pond margins, damp soils and certain sorts of herbivore dung. Most Culicoides species of veterinary importance tend to breed in organically enriched, damp soil, such as is found adjacent to their hosts in and around farm holdings. There are about 1500 known Culicoides species, but only around 50 have been shown to be capable of developing a fully disseminated transmissible BTV infection. The ability to act as an effective vector of BTV further requires that the species feeds mainly or wholly upon ruminants and occurs in large numbers. As a result, only a handful of Culicoides species are thought to be able to act as effective vectors in the field. These include $C$. imicola (the principal vector in Africa, the Middle East, much of southeast Asia and parts of southern Europe), C. sonorensis (BTV vector in North America) and C. brevitarsis (the principal vector in Australia) (33).

BT is endemic in many tropical, sub-tropical and temperate regions of the world (Africa, southern Asia, Australia, the Middle East, and the Americas), between latitudes $40^{\circ} \mathrm{N}$ and $53^{\circ} \mathrm{S}$, during times of the year that are optimal for vector activity (30). BTV is currently circulating in sub-Saharan Africa, Turkey and the Middle East, in close proximity to the European continent. These virus-affected areas have been connected to Europe by synoptic wind systems and traditional livestock trade routes. The potential for BTV spread to Europe has therefore long existed - either by the movement of infected ruminants or by the wind-dispersal of infected midges. Historically, BT has made only brief sporadic incursions into Europe, involving a singlevirus serotype on each occasion (16). However, since 1998, this range has extended gradually further north (as far as $44^{\circ} \mathrm{N}$ ) into areas of Mediterranean Europe and the Balkans, involving five different BTV serotypes: 1, 2, 4, 9, and 16 (14). Between 1998 and 2005, BTV entered Europe from at least two origins and spread up to $800 \mathrm{~km}$ further north in Europe than ever before. It has been suggested that this spread has been driven by the recent changes in European climate, which have allowed increased virus persistence during winter, the northward expansion of $C$. imicola, and, beyond this vector's range, transmission by indigenous European Culicoides species - thereby expanding the risk of transmission over larger geographical regions (23). Climate has a long-term indirect effect on the transmission of BT via its effects on the distribution and availability of suitable habitats. Adults of $C$. absoletus appear to favour shaded leafy habitats such as forest, while species such as $C$. imicola prefer sparsely vegetated areas in full sunlight (4). The time required by Culicoides to digest a blood meal and thus the interval between feeding is a function of ambient temperature (21). The biting rate is a particularly significant parameter for pathogen transmission because it appears twice in the transmission cycle, being a prerequisite for both vector-host and host-vector transmission events. The ambient temperature also determines the rate of viral RNA-polymerase activity and hence virus replication rate, and thereby the time required for ingested virus to reach the salivary glands.

In order to explain the effect of climatic changes on BTV transmission in the Mediterranean basin, the various responses of biological processes involved in the life-cycle of Culicoides and in the transmission cycle of BTV to climate should be considered. In the case of vector-borne diseases such as BT, key events in both cycles are modulated by temperature and moisture availability $(17,34)$. It is well known that warm temperatures enhance the recruitment, development, activity and survival rates of Culicoides vectors (18). Significantly, the competence of Culicoides vectors, both the degree of transmission and the extension of transmission, is enhanced by warm temperatures (35). Within traditional vectors, warm temperatures increase viral replication rates and may reduce the efficiency of heritable barrier mechanisms that constrain virus dissemination through a vector individual at various stages following oral infection. BTV can persist at low temperatures $\left(<10^{\circ} \mathrm{C}\right)$ for up to 35 days inside adult vectors and later replicate and be transmitted when the temperature increases (18). An increase in the cumulative frequency of either warm or hot periods in summer/ autumn or whilst overwintering as larvae or adults will increase the transmission potential of these vectors for BTV. Moisture availability is the second most important extrinsic variable affecting Culicoides vectors, and therefore also BTV transmission. Precipitation 
governs the size and persistence of semi-aquatic breeding sites for larvae, as well as the availability and duration of humid microhabitats where adults can carry out key activities and shelter from desiccation (17). Whether changes in precipitation act as climatic drivers of transmission is likely to vary geographically according to the habitat preferences of the vectors in the region and the average suitability of breeding sites there. Thus, precipitation increases might favour increased breeding in arid areas, but across the Mediterranean, the presence of Culicoides can be matched statistically to areas that are relatively dry in summer (22). For indigenous European Culicoides spe-

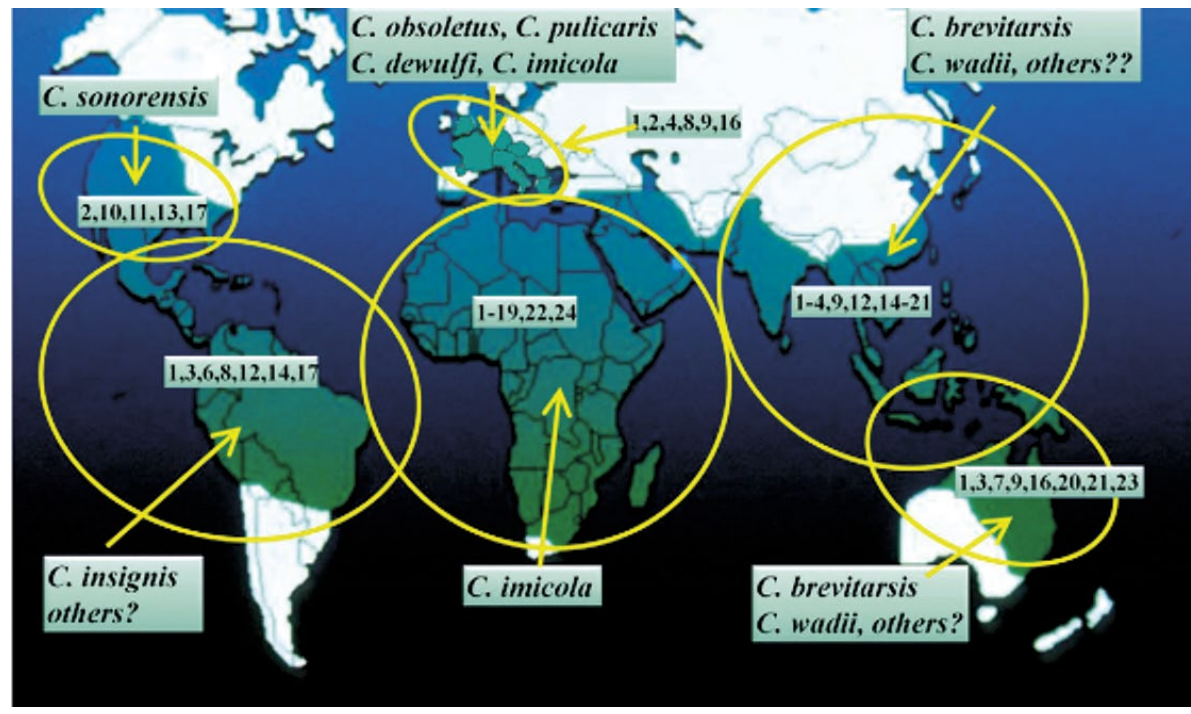

Fig. 1. The worldwide distribution of BTV serotypes and the Culicoides vectors (modified, according to Tabachnick (29))

cies, however, conditions of high humidity may enable adult midges to resist desiccation during increasingly warm summers. Increases in temperature and precipitation may lead to an increased geographical and seasonal incidence of BTV transmission. It can occur as a result of an increase in the range, abundance and seasonal activity of vectors, as well as increases in the proportion of the vector species that is competent and increases in the development rates of the virus within vectors. BT incidence in the south of Europe has increased most markedly in areas where temperature has risen by at least $1{ }^{\circ} \mathrm{C}$ since the $1980 \mathrm{~s}$ - in Italy, adjacent west Mediterranean islands and in the Balkans $(8,9)$.

BTV extension into north-western Europe is undoubtedly one of the best examples of the possible influence of weather, and perhaps climate change, on a vector-borne disease episystems (25). In August 2006 , for the first time, BTV passed the latitude $50^{\circ} \mathrm{N}$ and the disease caused by BTV serotype 8 occurred in the Netherlands, Belgium, Germany, France and Luxembourg. The sequence analysis of the BTV-8 genome suggested a close similarity to a strain of this serotype previously isolated from sub-Saharan Africa (11). There are several theories explaining its introduction, for instance, import of animals at the viraemic phase of the disease, infected semen or embryos, inadvertent shipment of infected biting midges together with animals or plants, or the introduction of Culicoides vectors through their own flight over long distances or with the aid of wind (26). In 2007-2008 , the BT situation changed for the worse - BTV-8 spread to the other regions of Europe, the number of outbreaks increased rapidly (about 50,000 cases of the disease were reported), and new BTV serotypes 1 and 6 were detected $(26,33)$. The spread of BTV in these areas could have been influenced by a number of factors, primarily the climate change (increase in the average annual temperature and humidity) causing the expansion of the vector $C$. imicola. It has also been

proven that other species of biting midges: C. obsoletus, C. pulicaris and C. dewulfi can also be vectors of BTV (15). The extensive overlap with the distribution of the Palearctic vector complexes indicates a major (if not exclusive) role for these vectors during BT outbreaks, consistent with the isolation of the virus from wild-caught adult midges in outbreak areas (14, $15)$. It is clear that climate change (increasing mean winter temperature) probably played a prominent role in the spread of BTV throughout Europe, though it is less clear precisely what the role of climate might have been in influencing other episystem factors, such as changes in animal management practices, increases in susceptible wildlife populations, increases in exotic animal theme parks, and implementation of BTV vaccination programmes (29). These climate changes affect the worldwide distribution of the BTV serotypes and the different Culicoides vector species (Fig. 1). The BTV endemic regions have specific BTV serotypes associated with different Culicoides species - there are probably six different BTV episystems. In Europe, C. imicola, C. obsoletus, C. pullicaris and C. dewulfi are the primary BTV vectors, and there is a different suite of BTV serotypes: 1, 2, 4, 8, 9, 14 and 16 (29).

A variety of studies have described a link between changes in European climate during the first decade of the $21^{\text {st }}$ century and a possible link to the introduction and spread of BTV $(7,10,24)$. The European BTV episystem emerged coincidently with the significant warming trend in the region. Seven of the 10 warmest European winters occurred between 1998 and 2007, with the winter of 2006-2007 being the warmest on record (32). There is some evidence pointing to the role of indigenous European vector groups, primarily species from the $C$. obsoletus and $C$. pulicaris complexes, in BTV transmission in southern Europe. This includes the overlap of the distribution of these complexes with BT outbreaks $(10,24)$, isolation of the virus from adults of the C. pulicaris and C. obsoletus 
complexes $(15,28)$ and laboratory studies indicating competence levels for BTV comparable to that of C. imicola in some populations (3). These Palearctic vector complexes are widespread in northern Europe and overlap with both the major vector $C$. imicola and areas of historical BTV incursions across a wide geographical area. It is possible that the recent warming in Europe may have increased the importance of Palearctic vectors by increasing their population sizes and survival rates to compensate for their low competence levels and by increasing their individual susceptibility through developmental temperature effects. In support of this hypothesis, the areas where these Palearctic vectors have been involved in transmission again coincide with those areas of Europe that have warmed the most (23). Purse et al. (22) have applied an environmental envelope modelling approach to the analysis of the differential degree of overlap between the environmental envelope of BTV and each of its vectors and assuming that the distribution of the virus in environmental space would be closest to that of the vectors playing the greatest role in transmission. First, the current fine-scale distributions of BTV, C. imicola, $C$. obsoletus and C. pulicaris complexes across southern Europe and north Africa were mapped. Second, the key climatic factors that best define the current envelope of $C$. imicola were statistically determined. Third, the overlap of $C$. imicola's envelope (defined by these climatic factors) and areas of BTV transmission was compared to the overlap between the Palearctic vectors and BTV transmission. It was found that these Palearctic complexes had made a significant contribution to the transmission of BTV in southern Europe not only north of the range limit of $C$. imicola, but also inside this species' range - and had been instrumental in the spread of BTV to cooler and wetter regions of Europe (22). Moreover, the Palearctic complexes overlap extensively with the envelope of $C$. imicola. These studies also explained the seasonal conditions of temperature and precipitation that limit the distribution of C. imicola in different regions of the Mediterranean and environmental changes that would be required for its further northward spread in different areas. The results obtained for southern Europe suggested that further northward spread of BT after the mid 2000s would most likely depend on the portion of the distributions of species within the Palearctic complexes that BTV could occupy (determined by environmental effects on the viral replication and vectorial capacity of midge populations within these distributions). This was borne out in the summer of 2006, by the appearance of an African strain of BTV in north-western Europe (11).

It is assumed that BTV has evolved within stable, continental episystems where constituent vectors are able to transmit only indigenous viruses despite movements of hosts and vectors between episystems. As a result, the situation in Europe - of altered vector roles and widespread transmission of "foreign" strains - is deemed unusual. In fact, on some other continents, long periods of BTV faunal stability have been interrupted by the intermittent introduction and establishment of foreign or novel virus strains (23). The methods for predicting the arrival, establishment and spread of BTV in Europe were quickly developed during the BTV emergence in the 2000s. With regard to the process of its arrival, the development and analysis of large nucleotide and amino acid sequence databases for BTV have enhanced the ability to identify the origins of new viral strains entering Europe or circulating near the border of the continent (31). The arrival of new BTV strains due to the movement of animals and animal products is often hard to predict, as demonstrated by the unexpected appearance of BTV-8 in north-western Europe in 2006 (11).

Geographical and temporal variation in the probability of the establishment of BTV should be investigated within the framework of the basic reproduction number $-\mathrm{R}_{0}$, that is, the number of new cases that arise when a case is introduced into a native population. If climate changes affect vector-borne diseases, they will do so through the parameters and variables of the $\mathrm{R}_{0}$ equation (25). This approach requires a great deal of detailed knowledge on the rates of biological processes in the host and the vector and the ratio of vectors to hosts. Wilson et al. (31) have predicted when and where BTV might be transmitted under different temperature regimes on the basis of one of the key parameters of the $\mathrm{R}_{0}$ equation, that is, the extrinsic incubation period in the vector, and its relationship with temperature. The maximum extent of spread across northern Europe, where vectors are ubiquitous and abundant, might eventually be limited by thermal limits on BTV replication. A two-host one-vector model for $\mathrm{R}_{0}$, which incorporates information on the temperature dependence of biting rates, the extrinsic incubation period and vector mortality, was formulated by others (6). It was found, that $\mathrm{R}_{0}$ was highest between $20^{\circ} \mathrm{C}$ and $25^{\circ} \mathrm{C}$, but below $10^{\circ} \mathrm{C}$, vectors were unable to complete the extrinsic incubation period, whilst at high temperatures $\left(30^{\circ} \mathrm{C}\right.$ to $\left.35^{\circ} \mathrm{C}\right)$, high vector mortality limits $\mathrm{R}_{\text {. }}$. Moreover, Guis et al. (7) have developed a framework to quantitatively evaluate the effects of climate on BT's emergence in Europe by integrating high-resolution climate observations and model simulations within a mechanistic model of BT transmission risk. They provide a convincing model that correlates the climate variables of temperature and rainfall with many aspects of Europe's BTV epidemiology. The model provides a mechanistic insight into the BTV emergence across Europe, suggesting that its causes differ between distant regions of the continent. The authors further use their model to predict that under similar conditions and under the same model assumptions, the risk of BT in susceptible ruminants will rise in Europe due to the expected climate change and will cause an estimated $10 \%$ and $30 \%$ increase in the risk of BT in northwest 
and southwest regions of Europe, respectively, by the year 2050 (7). Recently, a comprehensive database of BTV case occurrences and an estimate of the global potential distribution of BTV under both current and future climate conditions have been developed (27). The study used outputs from 62 general climate models (GCMs) and four representative concentration pathway (RCP) scenarios from the AR5 of the IPPC to estimate the future potential distribution of the virus. Moreover, the ecological niche similarity among possible vector species and BTV case distribution in different geographical areas was tested to provide some level of assessment of the role of particular potential vector species in BTV transmission. The broad ecological niche and potential geographic distribution of BTV under present-day conditions reflected the disease's current distribution across the world in tropical, subtropical, and temperate regions.

To conclude, the spread of BTV and its vectors presents some of the strongest evidence that climate change is driving vector-borne diseases into new regions, as warming and disease spread have occurred at the same times in the same places. Changes in climate, that is, temperature, precipitation, humidity, wind, etc., can influence various aspects of the Culicoides vectors' life cycle, including survival, population numbers, vectorpathogen interactions, pathogen replication, vector behaviour and, of course, vector distribution. Different species of Culicoides have different environmental tolerances, and the optimal temperature and humidity levels for populations of Afro-Asiatic species, such as $C$. imicola, are different from those for Palearctic species, such as the $C$. obsoletus and $C$. pulicaris groups. Thus, a long-term environmental change may alter the suitability of a geographical region for some Culicoides species, changing its vector fauna and consequently the potential for the transmission of BTV. However, the biotic processes of changing vector roles and distribution have been as important as climatic process in driving the invasion of Europe by multiple BTV strains. The enhanced transmission of BTV by indigenous European vectors has been instrumental in the spread and persistence of infection in cooler and wetter areas of different regions of Europe after the invasion. The vectorial capacity of Culicoides is dynamic and climate-mediated, making it difficult to state unequivocally that particular species cannot or will not be involved in transmission - even of strains that enter Europe unexpectedly from geographically remote regions. The role of anthropogenic factors in mediating the emergence of BT in new areas remains poorly defined. Without a thorough characterization of all environmental and anthropogenic drivers of the recent emergence of BT in north-western Europe and elsewhere, it is difficult to predict what the future holds in terms of the global emergence of BTV infection. The results of recent studies by Brand at al. (2) on the future transmissibility of BTV in the United Kingdom (UK) show that when BTV first invaded northern Europe in 2006, the cumulative transmission intensity was higher than ever in the last 50 years, although with climate change such high risks are the expected norm by 2050 . Such predictions would indicate that regular BTV epizootics should be expected in the UK in the future. To improve predictions of climate change impacts on an infectious disease, more emphasis should be given to the integration of biomedical and ecological research for studying both the physiological and ecological mechanisms which mediate the climate change impacts on the disease, and to the development of harmonized methods and approaches to obtain more comparable results, as this would support discrimination between case-specific and general mechanisms (5). Most experts agree that using models for long-range predictions about complex factors, including variation within vector species, is likely to show differences over different spatial and temporal scales. The challenge is great, but it is naïve to expect that general findings about climate change can be extrapolated broadly when there is so much biological diversity in different episystems throughout the world. Humanity must be prepared for the effects of expected climate and environmental changes on vector-borne disease episystems. It is almost certain that BT transmission patterns will change in response to changing environmental conditions, including changes in weather and climate. Reducing global warming is clearly desirable for a variety of reasons. However, even reducing global warming would not necessarily decrease the risk of BT transmission, nor reduce future changes in disease episystems.

\section{References}

1. Bett B., Kiunga P., Gachohi J., Sindato C., Mbotha D., Robinson T., Lindahl J., Grace D.: Effects of climate change on the occurrence and distribution of livestock diseases. Prev. Vet. Med. 2017, 137, 119-129.

2. Brand S. P. C., Keeling M. J.: The impact of temperature changes on vectorborne disease transmission: Culicoides midges and bluetongue virus. J. R. Soc. Interface 2017. doi: 10.1098/rsif.2016.0481

3. Carpenter S. T., Lunt H. L., Arav D., Venter G. J., Mellor P. S.: The oral susceptibility to bluetongue virus of Culicoides (Diptera: Ceratopogonidae) from the United Kingdom. J. Med. Entomol. 2006, 43, 73-78.

4. Conte A., Goffredo M., Ippoliti C., Meiswinkel R.: Influence of biotic and abiotic factors on the distribution and abundance of Culicoides imicola and the Obsoletus Complex in Italy. Vet. Parasitol. 2007, 150, 333-344.

5. Gallana M., Ryser-Degiorgis M.-P., Wahli T., Segner H.: Climate change and infectious disease of wildlife: Altered interactions between pathogens, vectors and hosts. Curr. Zool. 2013, 59, 427-437.

6. Gubbins S., Carpenter S., Baylis M., Wood J. L., Mellor P. S.: Assessing the risk of bluetongue to UK livestock: uncertainty and sensitivity analysis of a temperature-dependent model for the basic reproduction number. J. R. Soc. Interface 2008, 5, 363-371

7. Guis H., Caminade C., Calvete C., Morse A. P., Tran A., Baylis M.: Modelling the effects of past and future climate on the risk of bluetongue emergence in Europe. J. R. Soc. Interface 2012, 9, 339-350.

8. Haylock M. R., Goodess C. M.: Interannual variability of European extreme winter rainfall and links with mean large-scale circulation. Int. J. Climatol. 2004, 24, 759-776.

9. Klein Tank A. M. G., Konnen G. P.: Trends in indices of daily temperature and precipitation extremes in Europe, 1946-1999. J. Climate 2003, 16, 3665-3680.

10. Liberato C. De, Purse B. V., Goffredo M., Scholl F., Scaramozzino P.: Geographical and seasonal distribution of the bluetongue virus vector, Culicoides imicola, in central Italy. Med. Vet. Entomol. 2003, 17, 388-394. 
11. Maan S., Maan N. S., Ross-Smith N., Batten C. A., Shaw A. E., Anthony S. J., Samuel A. R., Darpel K. E., Veronesi E., Oura C. A., Singh K. P. Nomikou K., Portgieter A. C., Attoui H., van Rooij E., van Rijn P., De Clercq K., Vandenbussche F., Zientara S., Breard E., Sailleau C., Beer M., Hoffman B. Mellor P. S., Mertens P. P.: Sequence analysis of bluetongue virus serotype 8 from the Netherlands 2006 and comparison to other European strains. Virology 2008, 377, 308-318

12. MacLachlan N. J.: The pathogenesis and immunology of bluetongue virus infection of ruminants. Comp. Immunol. Microbiol. Infect. Dis. 1994, 17, 197-206

13. Medlock J. M., Leach S. A.: Effect of climate change on vector-borne disease risk in the UK. Lancet Infect. Dis. 2015, 15, 721-730.

14. Mehlhorn H., Walldorf V., Klimpel S., Jahn B., Jaeger F., Eschsweiler J., Hoffmann B., Beer M.: First occurrence of Culicoides obsoletus-transmitted bluetongue virus epidemic in Central Europe. Parasitol. Res. 2007, 101, 219 -228 .

15. Meiswinkel R., van Rijn P., Leijs P., Goffredo M.: Potential new Culicoides vector of bluetongue virus in northern Europe. Vet. Rec. 2007, 161, 564-565.

16. Mellor P. S., Boorman J.: The transmission and geographical spread of African horse sickness and bluetongue viruses. Ann. Trop. Med. Parasitol. 1995, 89 $1-15$.

17. Mellor P. S., Boorman J., Baylis M.: Culicoides biting midges: their role as arbovirus vectors. Annu. Rev. Entomol. 2000, 45, 307-340.

18. Mellor P. S., Rawlings P., Baylis M., Wellby M. P.: Effect of temperature on African horse sickness virus infection in Culicoides. Arch. Virol. Suppl. 1998, $14,155-163$

19. Mellor P. S., Wittmann E. J.: Bluetongue virus in the Mediterranean Basin 1998-2001. Vet. J. 2002, 164, 20-37.

20. Mertens P. P., Maan N. S., Prasad G., Samuel A. R., Shaw A. E., Potgieter A. C., Anthony S. J., Maan S.: Design of primers and use of RT-PCR assays for typing European bluetongue virus isolates: differentiation of field and vaccine strains. J. Gen. Virol. 2007, 88, 2811-2823.

21. Mullens B. A., Holbrook F. R.: Temperature effects on the gonotrophic cycle of Culicoides variipennis (Diptera: Ceratopogonidae). J. Am. Mosq. Control Assoc. 1991, 7, 588-591.

22. Purse B. V., McCormick B. J., Mellor P. S., Baylis M., Boorman J. P., Borras D., Burgu I., Capela R., Caracappa S., Collantes F., De Liberato C., Delgado J. A., Denison E., Georgiev G., El Harak M., de la Rocque S., Lhor Y., Lucientes J., Mangana O., Miranda M. A., Nedelchev N., Nomikou K., OzkulA., Patakakis M., Pena I., Scaramozzino P., Torina A., Rogers D. J.: Incriminating bluetongue virus vectors with climate envelope models. J. Appl. Ecol. 2007, 44, 1231-1242.

23. Purse B. V., Mellor P. S., Rogers D. J., Samuel A. R., Mertens P. P., Baylis M. Climate change and the recent emergence of bluetongue in Europe. Nat. Rev. Microbiol. 2005, 3, 171-181.

24. Purse B. V., Nedelchev N., Georgiev G., Veleva E., Boorman J., Denison E., Veronesi E., Carpenter S., Baylis M., Mellor P. S.: Spatial and temporal distribution of bluetongue and its Culicoides vectors in Bulgaria. Med. Vet. Entomol. 2006, 20, 335-344.

25. Rogers D. J., Randolph S. E.: Climate change and vector-borne diseases. Adv. Parasitol. 2006, 62, 345-381.

26. Saegerman C., Berkvens D., Mellor P. S.: Bluetongue epidemiology in the European Union. Emerg. Infect. Dis. 2008, 14, 539-544.

27. Samy A. M., Peterson A. T.: Climate change influences on the global potential distribution of bluetongue virus. PLoS One 2016, 11.doi: 101371/journal. pone.0150489.eCollection 2016

28. Savini G., Goffredo M., Monaco F., de Santis P., Meiswinkel R.: Transmission of bluetongue virus in Italy. Vet. Rec. 2003, 152, 119.

29. Tabachnick $W$. J.: Challenges in predicting climate and environmental effects on vector-borne disease episystems in a changing world. J. Exp. Biol. 2010, 213, 946-954.

30. Walton T. E.: The history of bluetongue and a current global overview. Vet. Ital. 2004, 40, 31-38

31. Wilson A., Carpenter S., Gloster J., Mellor P.: Re-emergence of BTV-8 in northern Europe in 2007. Vet. Rec. 2007, 161, 487-489.

32. Wilson A., Mellor P.: Bluetongue in Europe: vectors, epidemiology and climate change. Parasitol. Res. 2008, 103, 69-77.

33. Wilson A. J., Mellor P. S.: Bluetongue in Europe: past, present and future Philos. Trans. R. Soc. Lond. B. Biol. Sci. 2009, 364, 2669-2681.

34. Wittmann E. J., Baylis M.: Climate change: effects on Culicoides-transmitted viruses and implications for the UK. Vet. J. 2000, 160, 107-117.

35. Wittmann E. J., Mellor P. S., Baylis M.: Effect of temperature on the transmission of orboviruses by the biting midge, Culicoides sonorensis. Med. Vet. Entomol. 2002, 16, 147-156.

36. Zientara S., Sailleau C., Viarouge C., Höper D., Beer M., Jenckel M., Hoffmann B., Romey A., Bakkali-Kassimi L., Fablet A., Vitour D., Breard E.: Novel bluetongue virus in goats, Corsica, France, 2014. Emerg. Infect. Dis. 2014, 20, 2123-2125.

Corresponding author: dr hab. Wiesław Niedbalski, assoc. prof., Wodna 7, 98-220 Zduńska Wola; e-mail: wieslaw.niedbalski @piwzp.pl 